\title{
Carbohydrate reserve and aerenchyma formation enhance submergence tolerance in rice
}

\author{
MHR Pramanik, IJ Shelley, D Adhikary, MO Islam \\ Department of Crop Botany, Bangladesh Agricultural University, Mymensingh 2202, Bangladesh
}

\begin{abstract}
An attempt was made to evaluate the submergence tolerance in rice using four Aman rice varieties viz. FR13A (local flood resistant, check), BRRI dhan 51 (HYV flood tolerant, check), BR 5 (HYV, susceptible) and a local aromatic rice,Ukunimadhu (local susceptible). Twenty days old seedlings of the rice varieties raised in earthen pots were submerged under $90 \mathrm{~cm}$ water depth in a submergence tank for 12 days and data were recorded on plant height, tiller number, carbohydrate reserve and internal anatomical structure of roots of the submerged and control (ambient) plants. Under submergence treatment Ukunimadhu showed rapid stem elongation with taller plants than the HYVs which showed shorter plant height. Tillering pattern was almost similar both in submergence treated and control plants in all the varieties. Variation in carbohydrate reserve was negligible among the varieties at ambient condition but the submergence treatment brought significant variation in carbohydrate content in them. Submergence treated FR13A and BRRI dhan 51 had the highest sugar and starch conservation ability while BR 5 and Ukunimadhu had the lowest. The higher reserved carbohydrate in the tolerant varieties might assist them to regenerate their normal growth rapidly after desubmergence. The cellular morphology of root tissue showed that intensity of aerenchyma development in submergence treated FR13A and BRRI dhan 51 was more pronounced compared to the local aromatic rice Ukunimadhu and perhaps this cellular large aerenchymatous development might be associated with the submergence tolerance of FR13A and BRRI dhan 51 than the local variety, Ukunimadhu.
\end{abstract}

Key words: Submergence tolerance, rice, carbohydrate reserve, root arenchyma

Progressive Agriculturists. All rights reserve

*Corresponding Author: habiburp@yahoo.com

\section{Introduction}

Rice is generally grown in three seasons (Aus, Aman and Boro) and Aman rice covers about 5.40 million ha contributing approximately $40 \%$ of total rice production in Bangladesh (Anonymous, 2011). Aman rice production is often affected by abiotic stresses like flood, submergence, etc. and flash flood regularly affects the rain fed low land rice ecosystem. About 15 million ha in the South and Southeast Asia (Neerja et al. 2007) and about 2.6 million ha of rain fed lowland areas rice lands in Bangladesh are unfavorably affected by excess water for incessant rainfall in monsoon season and periodically those go under water with complete submergence for 1-2 weeks or more covering about $24 \%$ of the total rice areas. This flood causes enormous damage to rice crop and irreparable yield loss from 10 to $100 \%$. This kind of inundation is generally known as submergence. Submergence tolerance is the ability of a rice plant to survive 10-14 days of complete submergence and renew its growth when the water subsides.

Submergence tolerance is a metabolic adaptation in response to anaerobiosis that enables cells to maintain 
their integrity so that the plants can survive hypoxia without major damages (Sarker et al., 2006). The increase in carbohydrates consumption for cell division, cell elongation and maintenance of elongated leaves (Voesenek, 2006) are adverse factors to escape the submergence adaptation. Characteristics determining submergence tolerance in rice and other plants include capacities for underwater photosynthesis, internal oxygen transport, anaerobic catabolism, shoot elongation response, and ability to recover after the flood water subside (Sarker et al., 2006; Voesenek, 2006).

Rice is a semi-aquatic plant, adapts to flood conditions through the formation of aerenchyma tissue which facilitates aeration of submerged root.Aerenchyma is constitutive meaning that it always forms during hypoxic environmental conditions. Constitutive aerenchyma occurs most frequently in the shoots and roots of wetland species. Hypoxia induces root aerenchyma production (Justin and Armstrong, 1987). Therefore, understanding the levels of aerenchyma formation in roots of tolerant and susceptible rice seedlings to cope with the complete submergence is an important aspect.In this manuscript we will present how different rice genotypes responded morphologically as well as metabolically under fortnight submergence stress.

\section{Materials and Methods}

\section{Experimental site and plant materials}

The experiment was conducted at the grill-house and Plant Ecology Laboratory of the Department of Crop Botany, Bangladesh Agricultural University, Mymensingh, during Aman season. The seeds of some selected varieties were collected from the Bangladesh Rice Research Institute (BRRI), Gazipur and some flood prone areas of Bangladesh.

\section{Treatments and design}

The treatments of the experiment consisted of four Aman rice varieties grown with submergence and ambient (control) condition. The varieties were a) flood resistant, FR13A, b) HYV BRRI dhan 51 (introgressed with $S U B 1$ gene, flood tolerant), c) flood susceptible BR5 and d) Ukunimadhu (aromatic rice). Thus, there were altogether eight treatments. The experiment was laid out in a Randomized Complete Block Design (RCBD) with three replications.

\section{Raising of seedlings and submergence treatment}

Seedlings were raised in earthen pots filled with field soil, cow dung and fertilizers. Pots were regularly watered to keep the soil moistened. Each pot contained 8 seedlings and finally three hills per pot were maintained. 20 days old seedlings were used for submergence treatment. Three pots of each variety were kept complete submerged condition in a concrete submergence tank maintaining water depth at $90 \mathrm{~cm}$ for 12 days. The rest three pots of each variety were grown in ambient condition as control. After 12 days of submergence treatment the pots were removed from the submergence tank and kept in ambient condition. Different intercultural operations like irrigation, fertilizer, weeding, insecticides application, etc. were carried out for better growth and development of the plants.

\section{Morphological study}

Plant height and tiller number per hill for the rice genotypes grown in submerged and control conditions were recorded considering three hills from each pot. Plant height from each pot was taken at different growth stages during the growth period at 15 days interval starting from 20 days after sowing (DAS) till 95 DAS. The plant height was measured from ground level to the top of the longest leaf at vegetative phase and to the top of the panicle at reproductive phase. Tiller number hill $^{-1}$ from three hills of each pot was counted during the growth period at 15 days interval till 95 DAS.

\section{Anatomical study of roots}

Immediately after de-submergence, roots of the submerged plants were collected and preserved in appropriate formalin and ethanol solution for future 
anatomical study in the laboratory. Anatomical investigation of the roots was carried out by preparing semi permanent slide. Transverse sections were made at 5 to $10 \mathrm{~mm}$ from root tips with a thickness of approximately $0.1 \mathrm{~mm}$. The root sections were examined and imaged under Olympus high resolution compound microscope aided with digital camera and computer.

\section{Determination of total sugar and starch content in the leaves}

Dried leaf samples collected from 35 days (ambient condition) and 5 days after de-submergence of the rice plants were ground finely by a grinding machine. After taking $1 \mathrm{~g}$ powder sample, it was soaked in $20 \mathrm{ml}$ alcohol and filtered with another $20 \mathrm{ml}$ alcohol. The filtrates were heated in water bath at $60^{\circ} \mathrm{C}$ for 20 minutes. The extract solution was made up to a volume of $100 \mathrm{ml}$ (stock solution). Four $\mathrm{ml}$ anthrone reagent solution was mixed with $1 \mathrm{ml}$ of the stock solution. After developing color, the solution was heated for 10 minutes and cooled in ice. When cooled, the absorbance was measured at $630 \mathrm{~nm}$. A calibration curve was plotted taking absorbance of standard sugar solution at different concentrations. This curve was used as the standard curve for the estimation of sugar content of the sample.

\section{Calculation}

The regression equation obtained from the standard curve is given below-

$\mathrm{Y}=4.85 \mathrm{x}+0.0382$

Where, $\mathrm{Y}=$ Light absorbance at $630 \mathrm{~nm}$

$$
\mathrm{x}=\text { Amount of glucose }(\mathrm{mg})
$$

The amount of sugar in the extracts was obtained from the regression equation by putting the respective absorbance values of the extracts and taking into consideration the appropriate dilution factor. The glucose content of the sample using standard curve was measured and the value was multiplied by 0.9 to get the starch content.

\section{Results and Discussion}

\section{Plant height at complete submergence}

Plant height is an important trait to cope with submergence tolerance. Figure 1 (a) reveals that rice plants grew well in the pots over the growth period at ambient/control condition. The aromatic rice, Ukunimadhu, had the highest plant height and the HYV flood tolerant cultivar, BRRI dhan 51 (referred in the text/fig. as BRRI 51), had the shortest plant height over the growth period. The local flood resistant, FR13A, possessed the intermediate plant height (Figure 1a). It reveals that seedling height did not increased significantly till 35 days for most of the genotypes under submergence treatment (20-32 days) except BR 5 and Ukunimadhu which increased in height during the submergence treatment due to rapid stem elongation follwed by a decline,as all the elongated stems did not erected properly (Figure 1b). Most of the genotypes showed enhanced shoot elongation in response to submergence as a means of regaining contact with the aeril environment and resuming photosynthetic carbon assimilation (Kawano et al., 2009). However, under flash flooding stem elongation is not enviable and limited stem elongation growth is found to be associated with genotypes ability to survive flash flooding (Ram et al., 2002). This is probably due to the energy conservation during flooding for maintenance and survival processes. Thus, alternatively conservation of stored carbohydrates in stem is a quiescence strategy of not elongating quickly in response to short term inundation. It conserves carbohydrate reserve elsewhere in the plant that may then be used after the submergence is over. The low shoot elongation of flash flood tolerant cultivars is controlled genetically. So, the slow growth in the varieties suppots their tolerance to short time submergence (Figure 1a \& b). On the other hand, the genotypes Ukunimadhu appears to be intolerant and possesses the physiological traits of fast underwater elongation that depletes carbohydrates in non-growing 
parts and transfers them to fast growing leaves as reported by Kawano et al. (2009).
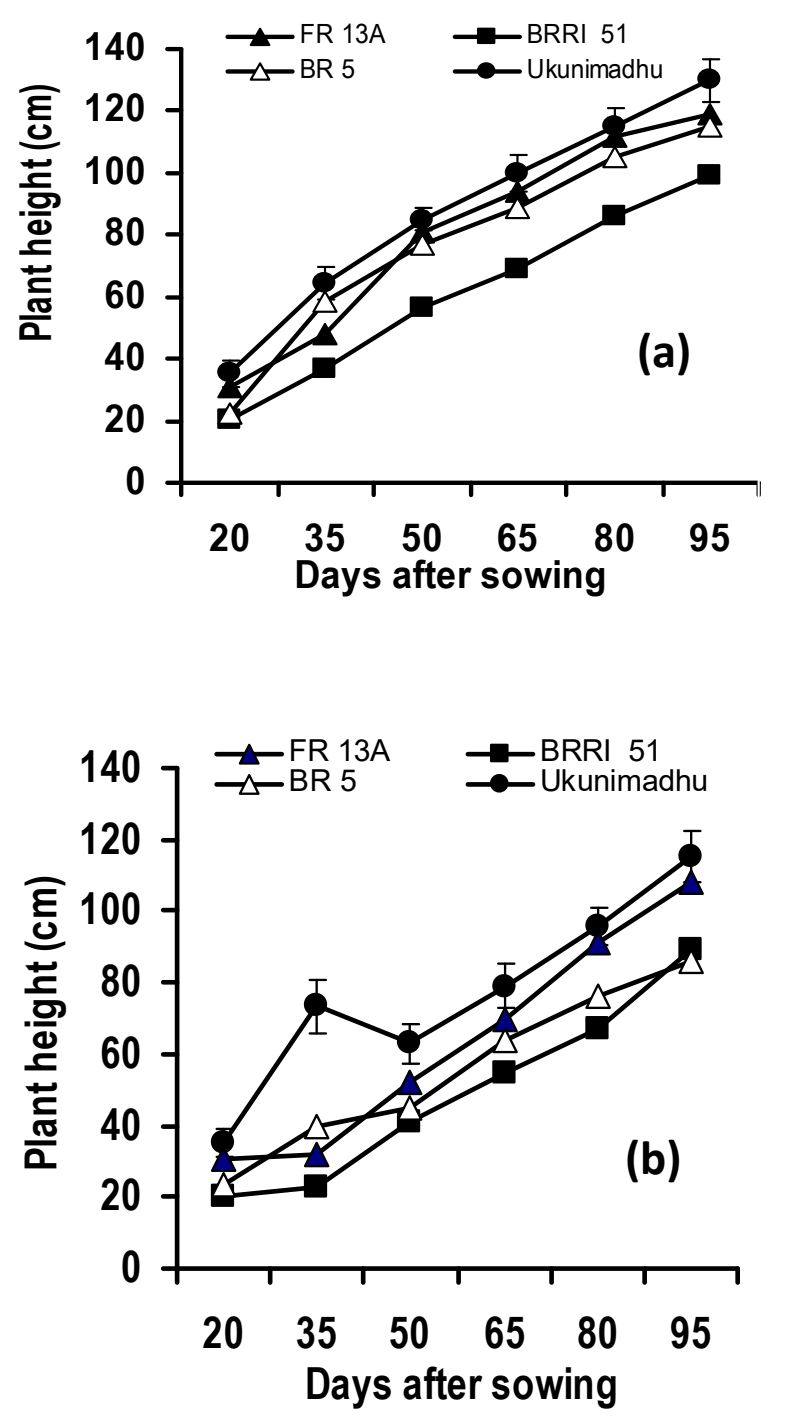

Figure1. Variation in plant height of rice genotypes over the growth period under ambient/control condition (a) and under complete submergence condition for 12 days at the seedling age of 20 days (b). Vertical bars represent standard deviation.

\section{Tiller number hill ${ }^{1}$}

Tiller number hill $^{-1}$ in the rice varieties was significantly affected by the complete submergence.
Tiller number in the seedlings remained almost static during submergence treatment (Figure 2a) compared to the rice varieties at ambient condition (Fig. 2b). Due to the submergence stress, shortage of light, oxygen, $\mathrm{CO}_{2}$, etc. had been reduced plant growth consequently tiller number per hill during the early growth stage but after few days ( $>35$ days) tiller numbers were increased rapidly like ambient condition (Figure $2 \mathrm{a}$ ). Increment of tiller number was almost linear in the other rice varieties at ambient condition (Figure 2b). Irrespective of genotypes there were significant differences in the number of tillers hill $^{-1}$ among the genotypes at all stages (Figure 2). The data revealed that FR13A and BRRI 51 produced the highest (13) number of tillers hill $^{-1}$ while BR 5 and Ukunimadhu produced the lowest number (10) of total tillers hill ${ }^{-1}$ at 95 DAS in controlled condition. On the other hand, submergence treated FR13A produced the highest (11) number of total tillers hill ${ }^{-1}$ and that of Ukunimadhu produced the lowest (6) number of total tillers hill ${ }^{-1}$ at 95 DAS. Actually total number of tillers hill ${ }^{-1}$ became high before the panicle emergence stage and then declined with advancing maturity. Lower number of tiller hill ${ }^{-1}$ due to submergence compared to ambient condition might be associated for the tillers formed could not survive during submergence. Yoshida et al., (1981) also found significant differences among the tiller number hill ${ }^{-1}$ in rice varieties due to shortage of light, nutrients, oxygen, $\mathrm{CO}_{2}$, etc. the initiated tillers could not be survived.

\section{Total starch content of leaves}

Starch concentration is an important factor for submergence tolerance in plants. Conservation of starch is needed for better survival of submerged plants. There was significant difference in starch content between the submerged and control plants (Figure $3 \mathrm{a} \& \mathrm{~b}$ ). At the age of 35 days starch content in the rice seedlings grown in the ambient condition was higher than that in submerged condition. FR13A and BRRI 51 produced highest starch content (about $38.5 \mathrm{mg} / \mathrm{g} \mathrm{DM}$ ) followed by the other varieties (BR 5 
and Ukunimadhu) about $32 \mathrm{mg} / \mathrm{g}$ DM. Interestingly in submerged condition starch content in FR 13A and BRRI 51 slightly reduced (about $36 \mathrm{mg} / \mathrm{g}$ ) and in the other varieties (BR $5 \&$ Ukunimadhu) starch reduced to about $45 \%$ due to the submergence stress.
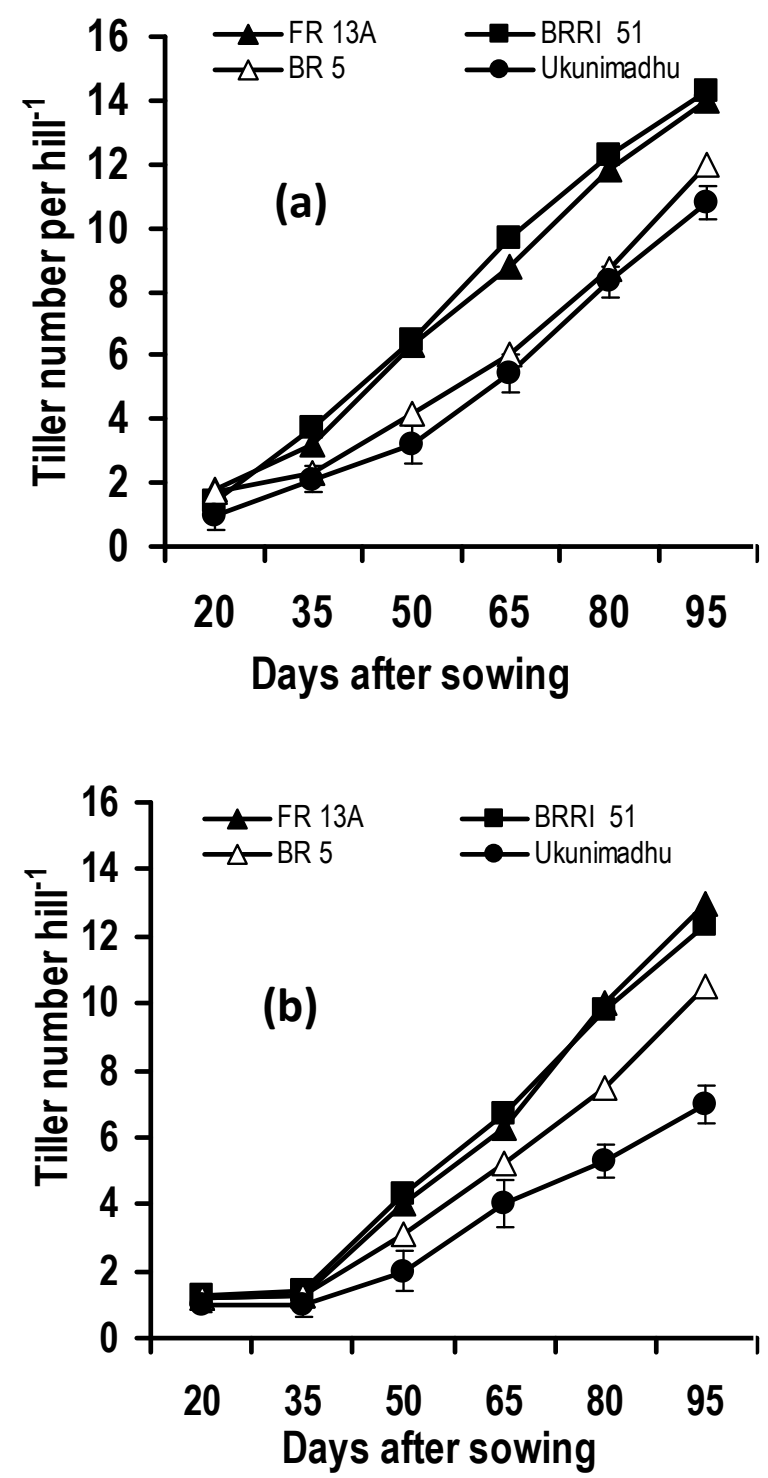

Figure 2. Changes in tiller number per hill at ambient condition (a) and in response to complete submergence for 12 days (b) at the age of 20day old seedlings over the growth period. Vertical bars represent standard deviation.

\section{Total sugar content of leaves}

Sugar is an important source of energy in living beings. It is also an important factor for survival under waterlogged condition for submergence tolerant cultivars. As FR13A and BRRI 51 are submerged tolerant variety so they used little sugar in submerged condition. On the other hand Ukunimadhu and BR 5 are supposed to be susceptible varieties. In ambient condition they had high soluble sugar content (about $4 \mathrm{mg} / \mathrm{g} \mathrm{DM}$ ) but in submerged condition their sugar content declined to $<3 \mathrm{mg} / \mathrm{g}$ DM (Figure $3 b$ ). Starch concentration before or during submergence can support the significant role for plant survival during submergence. This starch variation is created by low light intensity, water turbidly, water depth, $\mathrm{CO}_{2} \& \mathrm{O}_{2}$ concentrations, seedling age, alcoholic fermentation and above all this variation is created by genetic makeup of the test plants. Carbohydrate concentration before and during submergence has long been recognized as an important factor of submergence tolerance in rice (Kawano et al., 2009; Ram et al., 2002). An increased capacity to utilize sugars through the glycolytic pathway enables rice seedlings to survive longer periods of flooding (Ito et al., 1999). The nonstructured carbohydrates are utilized during submergence to supply the required energy for growth maintenance metabolism (Huang et al., 2005). The result of our experiment support the aforesaid findings. Carbohydrate remaining after submergence will presumably be especially important in recovery growth after submergence (Singh and Singh, 2001; Ram et al., 2002; Das et al.,2005).

\section{Aerenchyma formation in root under submergence}

Our results reveal that the genotypes FR13A and BRRI 51 (introgressed with SUB1 gene) both developed numerous aerenchyma during submergence while in control/ambient condition they had little aerenchyma (Figure 4). On the other hand, the aromatic genotype, Ukunimadhu, had less aerenchyma both in ambient and subnmerged conditions although in submerged 
condition large air cavities were noticed (Figure 4). Anatomical and morphological adaptations in roots is formation of arenchyma which allows ventillation of submerged organs and lessen or even avoid the impact of water logging and flooding. The most studied plastic response to flooding is the formation of aerenchyma in the root cortex (Justin and Armstrong, 1991; Striker et al., 2007).

The development of aerenchyma in roots under flooding is thought to be an adaptive trait for submergence tolerance (Shimamura et al., 2003; Nikiand Gladish, 2001; Chen et al., 2002, Setter and Waters, 2003; Shuwen et al., 2006). This allows plants to transport to atmospheric oxygen to the underground organs to maintain aerobic respiration and to oxidize various reducing compounds in the rhizosphere (Pezeshki, 2001). The development of aerenchyma may be are sponse to flooding in both flood tolerant and intolerant species (Schussler and Longstreth, 2000; Chen et al., 2002; Evans, 2004). Most rice genotypes die within several days of being completely submerged, but some genotypes, such as FR13A is more tolerant of submergence (Mazaredo and Vergara, 1982). FR 13A's tolerance is conferred by a major quantitive trait locus designated SUB1 situated on chromosome 9 (Siangliw et al., 2003; Xu et al., 2006). The genotypes FR13A and BRRI 51 (introgressed with SUB1 gene) both developed aerenchymathough more intense aerenchyma were found in FR13A during submergence while in control/ambient condition they had little aerenchyma. On the other hand, the aromatic genotype, Ukunimadhu, had less aerenchyma both in ambient and subnmerged conditions although in submerged condition large air cavities were noticed as was reported by many researchers (Chen et al., 2002; Evans, 2004).

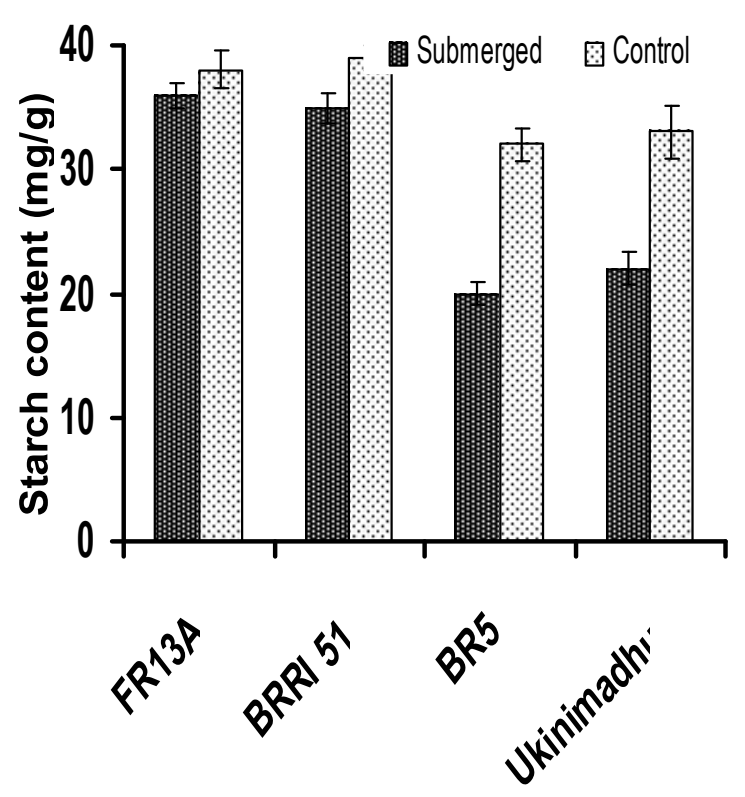

Figure 3.a. Variation in starch content in the rice leaves after submergence stress at the age of 35 days after sowing. Vertical bars represent standard deviation.

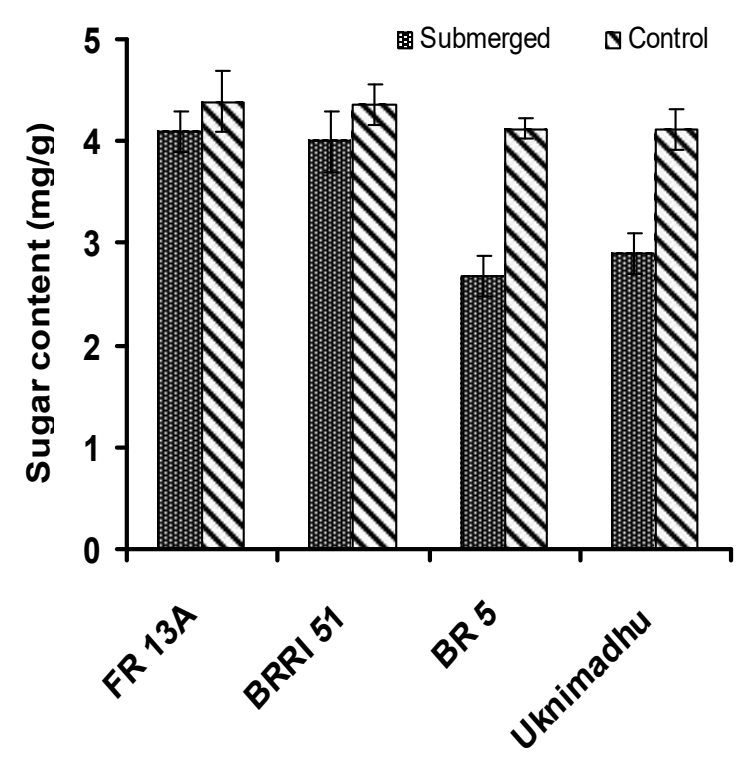

Figure 3.b. Variation in sugar content in the rice leaves after submergence stress at the age of 35 days after sowing. Vertical bars represent standard deviation. 


\section{Ambient condition (control)}
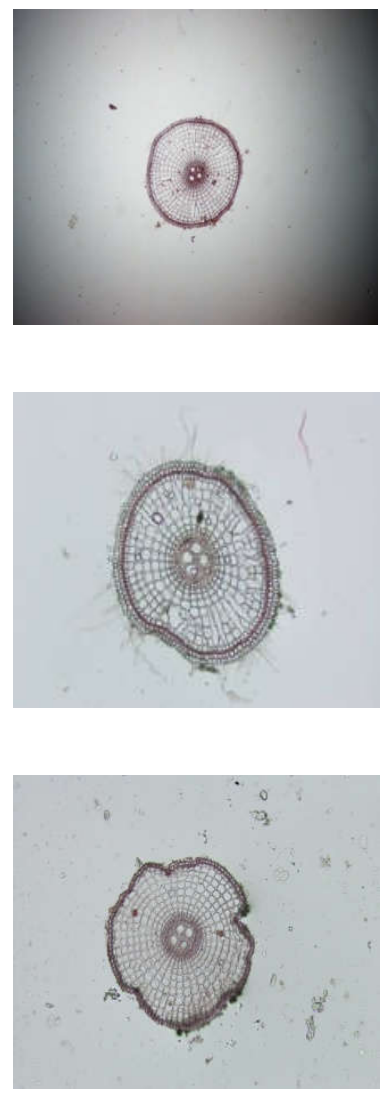
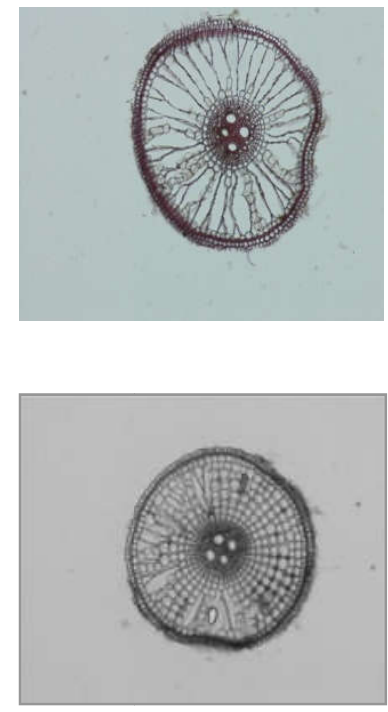

Submerged
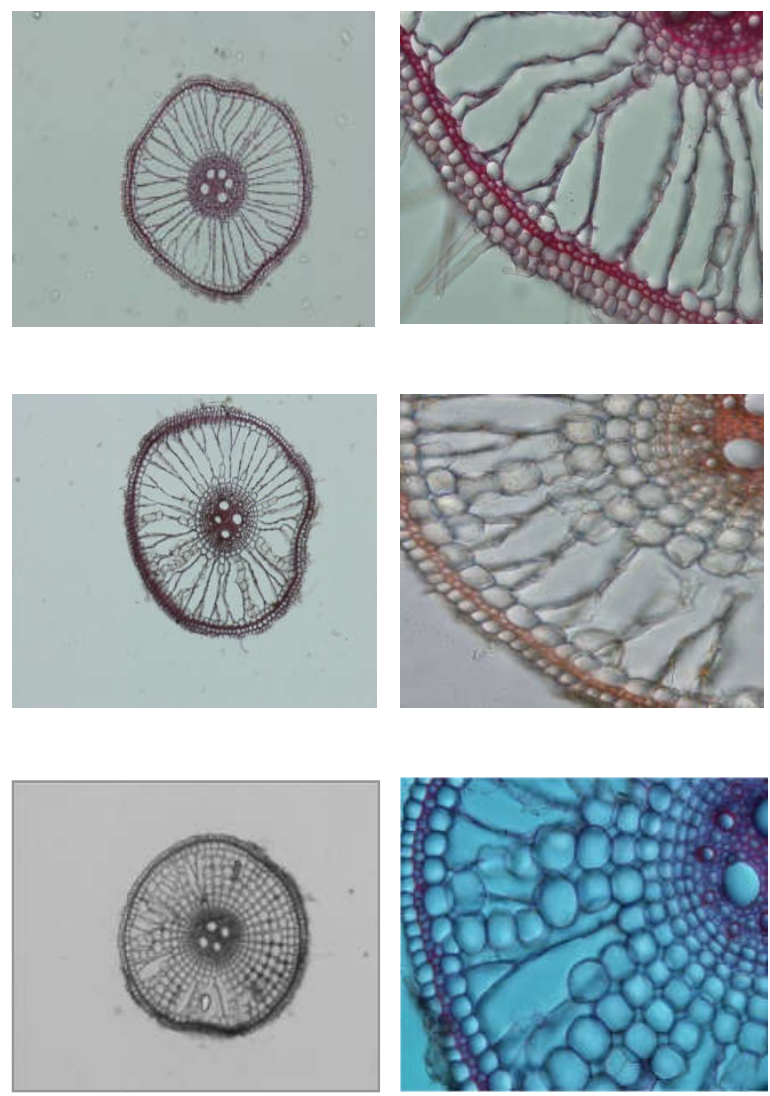

FR 13A

(local resistant)

\section{BRRI 51 \\ (HYV tolerant)}

Figure 4. Cross sections of the growing root tips (at 5-10 $\mathrm{mm}$ away from root apex) of the rice seedlings at 32-day old [varieties; FR 13A, local flood resistant; BRRI 51, HYV flood tolerant and Ukunimadhu, local aromatic variety] grown in ambient (control) condition and complete submergence stress for 12 days.

\section{Conclusion}

From this study it may be concluded that there is significant variation in morphological characteristics, carbohydrate contents as well as anatomical features among the genotypes for submergence stress. The genotypes FR13A and BRRI 51 did not exhausted their entire carbohydrate level even under the submergence stress like other genotypes and thus they are submergence tolerant; they also produced larger aerenchyma/air-cavity to cope with submergence stress. The most studied plastic response to flooding is the formation of aerenchyma in the root cortex. It is interesting to note that the varieties (FR13A and BRRI 51) produced larger air cavity/aerenchyma in root during submergence but the aerenchyma in them at ambient condition was very little or scanty. On the other hand, the local aromatic variety Ukunimadhu produced scanty aerenchyma at ambient condition, 
even under the same level of submergence stress. Aerenchyma development in other organs like stem and leaf including root at different levels of submergence stress might be more useful for valid conclusion. Finally, this study needs further experimentation in different condition like turbid water, high temperature, oxygen deficiency, longer submergence stress, etc. for exploiting their genotypic potential for submergence tolerance.

\section{References}

Anonymous (2011). In: Krishi Dairy. Agricultural Information Service. Khamarbari,Farmgate, Dhaka.Ek Nojore Bangladesh.

Chen H, Qualls R, Miller G (2002). Adaptive responses of Lepidium latifolium to soil flooding: Biomass allocation, adventitious rooting, aerenchyma formation and ethylene production. Environ. Exp. Bot.,48: 119-128.

Das KK, Sarker RK, Ismail AM (2005). Elongation ability and non-structural carbohydrate levels in relation to submergence in rice. Plant Sci., 168: 131-136.

Evans DE (2004). Aerenchyma formation. New Phytol., 161: 35-49.

Huang C, He W, Guo J, Chang X, Su P Zhang L (2005). Increased sensitivity to salt stress in an ascorbate dificient Arabiopsis mutant. J. Exp. Bot.56: 3041-3049.

Ito O, Ella E, Kawano N (1999). Physiological basis of submergence tolerance in rainfed lowland rice ecosystem. Field Crop Res., 64: 75-90.

Justin SHFW, Armstong W (1987). The anatomical characteristics of roots and plant response to soil flooding. New phytol., 106: 465-495.

Justin SHFW, Armstong W (1991). Evidence of the involvement of ethylene in aerenchyma formation and adventitous root of rice. New phytol., 118: 4962.

Kawano N, Ito O, Sakagami J (2009). Morphologica and Physiological responses of rice seedlings yo complete submergence (flash flooding). Ann. Bot., 103: 161-169.

Mazaredo AM, Vegera BS (1982). Physiological difference in rice varities tolerance and susceptible to complete submergence.In:Proceedings of 1981 International rice workshop.Manila: Rice Research Institute, 327-341.

Neeraja CN, Magghirang-Rodriguez R, Pamplona A, Heuer S, Collard BCY, Septiningsih EM, Vegara G, Sanchez D, Xu K, Ismail AM, Mackill DJ (2007). A marker assisted backcross approach for developing submergence tolerant rice cultivars. TAG-online DOI 10.1007/s00122-007-0. 10p.

Niki T, Gladish DK (2001). Changes in growth and structure of pea primary roots (Pisum sativum L) as a result of sudden flooding. Physiol. Plant, 42:694-702.

Pezeshki SR (2001). Wetland plant responses to soil flooding. Environ. Exp. Bot.,46: 299-312.

Ram PC, Singh BB, Singh AK, Singh PN, Singh, HP (2002). Physiological basis of submergence tolerance in rainfed lowland rice: Prospects of germplasm improvement through marker aided breeding. Field Crops Res., 76:131-152.

Sarker RK, Reddy JN, Sharma SG, Abdelbagi, M, Ismail (2006). Physiological basis of submergence tolerance in rice and implications for improvement. Current Sci., 91:7: 899-906.

Schussler EE, Longstreth DJ (2000). Changes in cell structure during the formation of root aerenchyma in Sagittaria lancifolia (Alismataceae). American J. Bot., 87:12-19.

Setter TL, Waters I (2003). Review of prospects for germplasm improvement for waterlogging tolerance for wheat, barley and oats. Plant Soil, 253: $1-34$.

Shimamura S, Mochizuki T, Nada Y, Fukuyam, M (2003). Formation and function of secondary aerenchyma in hypocotyls, roots and nodules of sobyean under flooded conditions. Plant Soil, 251:351-359. 
Shuwen LLT, Pezeshki SR, Shield FD, (2006). Partial flooding enhances aeration in adventitious roots of black willow(Salixnigra) cuttings. J. Plant Phys., 163:619-628.

Siangliw M, Toojinda T, Tragoonrung S, Vanavichit A (2003). Thai jasmine rice carrying QTL $_{\mathrm{ch}} 9$ (sub QTL) is submergence tolerant. Ann. Bot., 91: 255261.

Singh DK, Singh V (2001). Seed size and adventitious (nodal roots) as factors influencing the tolerance of wheat to waterlogging. J. Agric. Res. Australia, 54:969-977.

Striker GGP, Insaustl AA, Grimoldi, Vega AS (2007). Trade-off between root porosity and mechanical strength in species with different types of aerenchyma. Plant Cell Environ.,30:580-589.

Voesenek LAC J (2006). Tansly review. How plants cope with complete submergence. New Phytol.,170: 213-226.

$\mathrm{Xu} \mathrm{K}$, Xun X, Fukao T, Canlas P, MaghirangRodriguez R, Heuer S (2006). Sub 1A is an ethylene response factor like gene that confers submergence tolerance to rice. Nature, 442: 705708 .

Yoshida S, Forno D, Cock J, Gomez KA (1981). Laboratory manual for physiological studies in rice. International Rice Research Institute, Los Banos, Philippines. 